\title{
A conference of our own \\ Creating an in-house professional development opportunity
}

f your library is like ours, your staff has

many and varied skills and talents. Most of our library staff participates in professional development activities-conferences, webinars, networking, etc. But, as a small library, our day-to-day tasks often dominate our schedules, and, even with regularly scheduled meetings, we aren't often able to share and investigate new ideas, conduct research, or teach each other new things.

A librarian at Aquinas College in Grand Rapids, Michigan, Christina Radisauskas, decided to rectify this situation. She had recently served on two conference planning committees, working as the events committee chair for a regional academic libraries conference and as the planning committee cochair of a national conference. Fresh off those experiences, Radisauskas came up with the idea of organizing a conference just for our library. Her concept was for library staff to dedicate a day to sharing, teaching, and exploring with each other. This conference would take advantage of our individual areas of interest and provide a formalized venue for us to present on topics that we felt might be compelling and beneficial to others. Her idea was enthusiastically embraced by several of her colleagues, so she, along with library Codirector Francine Paolini, began to plan the event.

Radisauskas was the ideal person to adapt the procedures of a large event to fit the needs of our much smaller effort. She had a clear vision of what she wanted to achieve and knew what was required to implement that vision. As a result, she created a program with enough structure that staff understood it to be a legitimate professional development opportunity, yet with enough informality that participation wasn't unduly onerous.

It was decided in June to hold a full day conference in July, traditionally a time of the year when staff have some flexibility in their schedules. This gave the planners (and presenters) about six weeks to prepare.

\section{Planning the conference}

Modeled on the variety of lengths and types of presentations available to speakers at the national conference, the planners elected to offer two different presentation categories for our event (standard presentation and interactive workshop) and three durations: a seven-minute "lightning talk," a 30-minute session, and a 45-minute session. This offered flexibility to those who did not have time to prepare a longer research-based presentation (or whose topic did not lend itself to a longer discussion), but still wanted to be involved. An email invitation to participate was sent to all library staff, including librarians, paraprofessionals, and part-time workers (library student assistants were not part of this inaugural event). People were free to present alone or in groups. And, even if they weren't presenting, all staff were welcome to attend.

Similar to the process of calling for pro-

Shellie Jeffries is library codirector, email: shellie.jeffries @aquinas.edu, and Christina Radisauskas is associate instruction and outreach librarian, email: radischr@aquinas. edu, at Aquinas College in Grand Rapids, Michigan

(C) 2015 Shellie Jeffries and Christina Radisauskas 
posals when planning a larger conference, presenters were asked to submit proposals for their sessions by a deadline. A Google submission form was created, which prompted presenters to state their names, select a presentation type and length, provide a title, and write a description. The chances of a proposal being turned down were very slim, since our library staff is so small (seven librarians, six support staff), but requiring that proposals be submitted ensured that topics weren't duplicated. It was also extremely helpful to have all the proposals in one document, when it came time to schedule the sessions.

Responses to the call were slow to come in and a few people had to be persuaded to participate, but in the end ten proposals from eight staff members were submitted, supplying enough content that we were able to plan a daylong event. A larger library might not have the luxury of accepting every proposal received, but we had just enough — and a sufficient variety-to accept all that came in. Topics ranged from a Screencast-OMatic demonstration to a discussion of ebook considerations to an overview of the college archives (housed in the library) to a pictorial history of our library. Presenters selected a diversity of presentation categories, which meant the conference would be a dynamic collection of different types of sessions. The planners created a schedule with ten-minute breaks between sessions, allowing people to check emails, make phone calls, and otherwise attend to their regular work, if needed. The schedule was a Google doc shared with all library staff.

The original plan was to have all the presentations take place in the library's computer classroom. However, that room had been previously reserved for another purpose, so the planners found a different location for the mid-morning sessions. Our library is connected to a classroom building, so it was easy to relocate to an empty room (another advantage of holding the event during the summer). What at first seemed an inconvenience became serendipitous-hold- ing the presentations in a new environment offered a change of pace, shook up seating arrangements, and re-energized everyone.

Following the adage "If you feed them, they will come," the library covered the cost of breakfast (coffee and pastries) and lunch. The planners picked up the pastries in the morning and established coffee service in the classroom 30 minutes before the first presentation.

To make the day special, sandwiches were ordered from a restaurant not often frequented by library staff. Attendees selected their sandwiches the day before the event, and one of the planners picked up the order prior to the lunch break. Eating lunch together became an unanticipated bonding experience as all the attendees sat around a table and had a chance to converse casually with each other.

On the day of the event, the bulk of the set-up and administrative work fell to the conference planners. They directed and corralled the attendees throughout the day to keep things moving. Drawing on her conference planning experience, Radisauskas understood the importance of time-keeping to ensure that an event stays on track, and she designated herself the official timekeeper for the conference. She was strict about staying on time, employing the technique of notifying presenters with signs when they had 5, 2 , and 1 minute left. As a result, the program ran smoothly and on schedule.

\section{Evaluations}

Following the conference, an evaluation form was sent to all attendees, asking for feedback about timing, content, topics, and suggestions for improvement. All attendees agreed or strongly agreed that the conference was well-organized; that the topics presented were varied, relevant, and interesting; and that we should hold another conference next year. Comments included:

"I think the day was fun and very informative. For next year, perhaps we can consider putting together packets consisting of all the handouts for the day. And maybe 
we can have some sort of takeaway for the day. Like the conference day equivalent of a party favor. Great job."

"The different types of presentations (demo, lightning rounds, lecture) created a varied conference that was never boring. For a first time attempt, it was really well done and I don't have any suggestions for improvement."

"Perfectly organized and run. Having brief breaks between each presentation was incredibly valuable, and having each person start on time was wonderful....Everyone's different style of presenting kept things fun and interesting."

"Liked the ten-minute breaks between presentations. Liked having some in the classroom and some in JLH room. Maybe next year we can have one or two in [room] 302 also."

"Excellent way for us to communicate to each other, great learning opportunity, really got a lot out of it!"

\section{Lessons learned}

Some of the things that contributed to the success of our conference were:

- Get buy-in from library administration and a few enthusiastic staff members. The director can "encourage" participation from library staff and if there are a few interested people, you won't run the risk of nobody signing up to present.

- Allow people to present whatever and however they want. This is a day of learning but also a day of fun. Those who think outside the box add spice.

- Encourage all staff (not just librarians) to participate. Support staff are often overlooked when it comes to professional development opportunities. One of our most creative presentations came from a part-time staff member who talked about a workshop she had attended on hiring student workers.

- Establishing a more formal structure (requiring proposals, developing a schedule, etc.) created an atmosphere that encouraged presenters to take their talks seriously, treating the conference and their audience with respect. The effort everyone put into making their sessions engaging and informative was apparent. It should be noted that presenting at this internal conference required nearly as much preparation time as for any larger conference, so volunteering to participate should not be taken lightly.

- It is essential to stay on schedule. Make sure to have a timekeeper, and be clear that presenters are expected to adhere to their allocated time frame.

- Food always makes an event even more enjoyable. Lunching together provides a great opportunity for the staff to coalesce as a team.

- Ask for feedback after the event with an anonymous evaluation form (e.g., via Google Drive or SurveyMonkey). Find out if people think this is something they'd want to do again and encourage suggestions on how to do it better next time.

\section{Suggestions}

While the conference was very well received, we would change a few things for the next conference we plan:

- Encourage presenters to test their presentation in their scheduled rooms so that unexpected issues with technology can be resolved prior to the event.

- Take photographs. Especially during the more engaging activities. Post them on relevant social media and perhaps include them in the library's annual report.

- Thank people, both presenters and attendees, in writing for attending. People took time out of their busy schedules to participate or attend the event, and expressing gratitude is a positive way to wrap it up.

\section{Conclusion}

Planning an internal library conference can be a relatively straightforward process, requiring a moderate investment of time to organize but resulting in a very rewarding experience for everyone who participates. Besides being an excellent team-building experience, and an occasion for professional development, it provides a low-stakes opportunity for librarians and staff to gain some presentation experience and test the waters for possibly presenting at regional or national conferences. $\boldsymbol{n}$ 